\title{
REPRESENTAÇÕES SOCIAIS DE ALUNOS ACERCA DA REDAÇÃO DO ENEM: PRÁTICAS DE ENSINO DE ESCRITA DO INSTITUTO FEDERAL DO PARANÁ
}

\section{SOCIAL REPRESENTATIONS OF STUDENTS ABOUT THE WRITING OF THE ENEM: WRITING TEACHING PRACTICES FROM ONE FEDERAL INSTITUTE OF PARANÁ}

\author{
Cláudia Cândido da Silva * \\ Carmen Teresinha Baumgärtner **
}

\begin{abstract}
Resumo: A redação do ENEM é um desafio a ser enfrentado pelos alunos concluintes do Ensino Médio. E na rede federal de ensino, preocupa-se com a formação de cidadãos críticos e reflexivos, munindo os alunos de todas as ferramentas possíveis para que ingressem no ensino superior. Neste estudo, discutimos os resultados parciais de uma pesquisa que objetiva analisar representações sociais que alunos do Ensino Médio, de um campus do Instituto Federal do Paraná (IFPR), produzem acerca da redação do ENEM. A fundamentação teórica está pautada na Teoria Dialógica do Discurso e na Teoria das Representações Sociais. Metodologicamente, é um estudo qualitativo, inserido no campo da Linguística Aplicada. O corpus foi gerado a partir de entrevista do tipo grupo focal, questionário e anotações em diário de campo. Os resultados indicam duas representações sociais sobre a redação: (i) há fórmulas mágicas para a escrita da redação do ENEM; (ii) a redação do ENEM é um castigo.
\end{abstract}

Palavras-chave: Redação do ENEM. Representações Sociais. Ensino. Instituto Federal.

\begin{abstract}
The writing of ENEM is a challenge to be faced by high school graduates. And in the federal education network, it is concerned with the formation of critical and reflective citizens, providing students with all possible tools to enter higher education. In this study, we discuss the partial results of a survey that aims to analyze social representations that high school students, from a campus of the Federal Institute of Paraná (IFPR), produce about the writing of ENEM. The theoretical basis is based on the Dialogical Theory of Discourse and the Theory of Social Representations. Methodologically, it is a qualitative study, inserted in the field of Applied Linguistics. The corpus was generated from a focus group type interview, questionnaire and field diary notes. The results indicate two social representations about the writing: (i) there are magic formulas that ensure success in writing ENEM; (ii) that the writing of ENEM is a punishment.
\end{abstract}

Keywords: Writing ENEM. Social Representations. Education. Federal Institute.

\section{Considerações Iniciais}

O foco de ensino na rede federal não tem como objetivo central a preparação para exames em larga escala como vestibulares e o Exame Nacional do Ensino Médio (ENEM, doravante); entretanto, uma das finalidades do Instituto Federal do Paraná (IFPR, de ora em diante) é "promover a integração e a verticalização da educação básica à educação profissional e educação superior, otimizando a infraestrutura física, os quadros de pessoal e os recursos de gestão" (BRASIL, 2008, p. 2). Nesse sentido,

\footnotetext{
* Professora do Instituto Federal do Paraná, campus avançado de Quedas do Iguaçu - PR. Mestranda pelo Programa de Pós-Graduação em Letras - concentração Linguagem e Sociedade - da Universidade Estadual do Oeste do Paraná (Unioeste), campus de Cascavel - PR. E-mail: claudia.silva@ifpr.edu.br

** Professora do Programa de Pós-Graduação em Letras - concentração Linguagem e Sociedade - da Universidade Estadual do Oeste do Paraná (Unioeste), campus de Cascavel - PR. E-mail: carmen.baumgartner@yahoo.com.br
} 
entendemos que ensinar práticas que promovam o acesso dos educandos ao ensino superior é também uma forma de cumprir com essa finalidade, pois disponibilizar ao aluno a oportunidade de refletir sobre a escrita da redação e analisar as representações sociais sobre elas pode auxiliar no acesso à educação superior.

A escrita de redação em exames de larga escala suscitou, de modo recorrente, polêmicas na história do ensino de escrita no Brasil. Um exemplo disso foi, segundo Soares (1978), a implantação da prova de redação nos vestibulares no ano de 1977 como uma solução para a insatisfação com o ensino da escrita, denunciada por jornais e revistas da época, os quais acusavam as escolas brasileiras de uma promoção decadente de ensino e aprendizagem da escrita. Com a redação do ENEM não é diferente. Todos os anos, após o certame, há grande repercussão nos meios de comunicação sobre o número elevado de notas baixas. Ao tratar sobre a redação do ENEM, a mídia expõe informações que podem, conscientemente ou não, serem apropriadas por estudantes, familiares, escola, governos, e pela sociedade em geral. Com isso, as pessoas formulam representações que passam a ser generalizadas como verdades, que poderão servir tanto para se chegar a melhores resultados, a depender das ações que serão empreendidas por todos, quanto para a manutenção dos resultados atuais.

De acordo com teóricos da Psicologia Social - Moscovici (2012 [1961], 2015 [2003]) e Jodelet (2001 [1989]), por exemplo -, representar um objeto é torna-lo familiar, encaixá-lo em uma categoria já existente em nosso universo, a fim de facilitar nossa relação com ele. Claro está que a redação do ENEM não é um objeto totalmente desconhecido dos estudantes do Ensino Médio (EM, deste ponto em diante); porém, é socialmente valorado e temido por seu caráter eliminatório (em caso de notas zero) e classificatório no ingresso ao ensino superior.

A escrita da redação tem motivado estudos de diversas áreas desde a década de 80 do século passado, a partir de autores como Geraldi (1984), Chiapinni (2000), Meserani (2002), os quais impulsionaram inúmeras pesquisas sobre o tema. Após a instituição da prova do ENEM, a partir de 1998, pesquisas se voltaram para a redação do ENEM, abordando desde temas propostos no exame, até a configuração do texto dissertativo-argumentativo ou as produções feitas pelos alunos, como Oliveira (2016), Paulinelli e Fortunato (2016) e Rodrigues (2017). Com menor frequência, há trabalhos, como este, que se dedicam ao estudo das Representações Sociais (RS, doravante) relacionadas à redação do ENEM. Por exemplo, Nogueira (2016) investigou as representações de alunos do EM sobre o processo de ensino-aprendizagem de Língua Portuguesa (LP, doravante) e Santos (2017) dedicou-se ao estudo das representações sociais de alunos da $3^{\text {a }}$ série do EM acerca do ENEM como um todo. Nosso interesse, entretanto, direciona-se para as RS que alunos do EM constroem sobre a escrita da redação do ENEM, levando-se em consideração a voz do aluno escritor da redação desse exame.

Dessa forma, o objetivo deste artigo é apresentar, de modo parcial, as RS acerca da redação do ENEM de alunos do $3^{\circ}$ ano do Curso de Informática Integrado ao Ensino Médio de um campus do IFPR. As reflexões estão alinhavadas a partir de duas vertentes teórico-metodológicas: (i) a Teoria dialógica do discurso, que nos permitirá discutir as relações entre linguagem, língua, sujeito e interação. As discussões nessa linha 
incluem os estudos e as pesquisas do Círculo de Bakhtin ${ }^{1}$, especialmente a partir dos estudos de Bakhtin (2011[1952-1953]) e Volóchinov (2017[1929]); (ii) e a Teoria das Representações Sociais, que nos auxiliará definir, como proposto por Moscovici (2012[1961], 2015) e Jodelet (2001[1989]), o conceito de RS. Sendo assim, esta pesquisa destaca-se por seu caráter interdisciplinar ao alinhar uma teoria da linguagem a uma da Psicologia Social.

Metodologicamente, trata-se de uma pesquisa qualitativa-interpretativista, na perspectiva teórica da Linguística Aplicada (LA), e de cunho etnográfico. A geração de dados ocorreu em um Instituto Federal localizado na região Centro-Sul do Paraná, durante um curso sobre redação do ENEM, ministrado de outubro a dezembro de 2018 para alunos do curso Técnico em Informática integrado ao EM. O corpus desta pesquisa consiste nos discursos de um grupo de 10 alunos do $3^{\circ}$ ano do EM, gravados em áudio durante uma entrevista do tipo grupo focal, das repostas a um questionário aplicado ao mesmo grupo com duas questões abertas e duas fechadas sobre a redação do ENEM e das anotações em diário de pesquisa.

Para elaboração deste texto, apresentamos um recorte de nossa pesquisa de mestrado $^{2}$, ainda em fase de desenvolvimento, cuja análise evidenciou duas representações produzidas socialmente pelos sujeitos da pesquisa. A primeira RS que identificamos a partir do corpus da pesquisa é a de que "existem receitas mágicas para escrever uma boa redação", e está ancorada dialogicamente na concepção de linguagem que trata a escrita de textos como processo de criação, como um dom criativo a ser estimulado no aluno. A segunda RS é a de que "a redação do ENEM é um castigo", dialogando com ideias e imagens arraigadas no inconsciente dos alunos sobre o uso da escrita em ambientes escolares, as quais indicam a escrita como punição.

Para apresentarmos os resultados desta investigação, este artigo encontra-se assim organizado: inicialmente, discutimos o conceito de RS; posteriormente, discorremos sobre conceitos da teoria dialógica a partir de autores do Círculo de Bakhtin; na sequência, indicamos alguns aspectos metodológicos deste estudo para, em seguida, analisarmos as representações construídas pelos alunos sujeitos desta pesquisa estudo; por fim, nas considerações finais, cotejamos os dados apresentados.

\section{As representações sociais}

Todos os conceitos, as imagens, as ideias ou as crenças que os estudantes têm sobre a redação do ENEM são oriundas do contexto social no qual estão inseridos, das suas leituras e das ideias veiculadas pela mídia. Eles absorvem todas essas informações e transformam-nas em RS acerca da prova de redação.

Representação Social é um conceito que advém da Psicologia Social, postulado por Serge Moscovici, a partir da publicação da sua tese de doutorado, em 1961,

\footnotetext{
${ }^{1} \mathrm{O}$ que hoje é conhecido como o Círculo de Bakhtin originou-se devido à união de um grupo de autores amigos de Mikhail Mikhailóvitch Bakhtin (1895-1975), como Valentin Nikolaevich Volochínov (18951936) e Pavel Medvedev (1891-1938), entre outros pensadores e pensadoras russos, que se reuniam regularmente nos períodos de 1919 - 1929 a fim de pensar, estudar e dialogar sobre questões relacionadas à linguagem, à literatura e à arte.

${ }^{2}$ A pesquisa foi aprovada pelo Comitê de Ética da Universidade Estadual do Oeste do Paraná, câmpus de Cascavel, sob o parecer $n^{\circ}$ 00987318.7.0000.0107.
} 
intitulada "A Psicanálise, sua imagem e seu público". Em seus estudos, ele investigou as RS que os franceses tinham sobre a psicanálise. Para tanto, interrogou 2.265 pessoas por meio de entrevistas e questionários, analisou também 1.640 artigos de 230 jornais e revistas de Paris e do interior da França (MOSCOVICI, 2012[1961]). Com base em seus dados, o autor compreendeu que o sujeito vive a realidade, interpreta-a e a externa em forma de representações, baseadas em seu conhecimento de mundo, em suas vivências e em seu contexto social. Para ele, a RS é uma das formas que o homem moderno tem de captar o mundo.

De acordo com o pesquisador, não se pode medir as RS, uma vez que elas se movem, são plásticas, transformam-se no decorrer do tempo e modificam-se nas interações dos variados grupos sociais. Com o passar do tempo, representações antigas podem ser substituídas por outras. Segundo ele,

\begin{abstract}
As imagens, as opiniões são normalmente definidas, estudadas, pensadas, unicamente por traduzirem a posição e a escala de valor do indivíduo ou da coletividade. Na realidade, trata-se somente de uma parte retirada da substância simbólica elaborada pelos indivíduos ou coletividades que, trocando suas maneiras de ver, tendem a se influenciar e a se remodelar reciprocamente (MOSCOVICI, 2012[1961], p. 46).
\end{abstract}

Como observamos no excerto, o autor indica que as RS nascem nas diversas maneiras de interagir que os sujeitos têm, nos seus variados grupos sociais, por meio da internalização das imagens, das opiniões e dos textos com os quais se deparam no dia a dia, transformando, consequentemente, esses elementos, após imprimirem suas valorações, em RS.

No mesmo sentido, Jodelet (2001[1989], p. 22) caracteriza as RS como "uma forma de conhecimento, socialmente elaborada e partilhada, com um objetivo prático, e que contribui para a construção de uma realidade comum a um conjunto social'. Para a autora, construir uma realidade comum e dar familiaridade ao estranho são funções das RS que também podem ser consideradas como uma forma que o homem moderno encontrou para interpretar o mundo em que vive.

Corroborando as ideias de Moscovici e Jodelet, o autor brasileiro Pedrinho Guareschi (2012[1961], p. 8) define as RS como "conjuntos de crenças e saberes socialmente construídos, socialmente partilhados, com os quais e através dos quais nós pensamos, falamos, decidimos fazer o que fazer, nos apropriamos do mundo e the damos sentido". De acordo com o autor, as RS são construídas socialmente, nunca no imaginário individual do sujeito, e também são socializadas com os grupos nos quais nos inserimos.

Representar um objeto é, de acordo com Moscovici (2015[2003]), torná-lo familiar por meio de dois processos: a ancoragem e a objetivação, respaldados em reminiscências que os sujeitos ou grupos têm, a partir de suas vivências, de suas histórias, de seus espaços e de seus contextos. A ancoragem consiste em "um processo que transforma algo estranho e perturbador, que nos intriga, em nosso sistema particular de categorias e o compara com um paradigma de uma categoria que nós pensamos ser apropriada" (MOSCOVICI, 2015[2003], p. 61). Ou seja, a ancoragem é o mecanismo que categoriza, classifica e nomeia o desconhecido. A objetivação, por sua vez, é o processo de "descobrir a qualidade icônica de uma ideia, ou ser impreciso; é reproduzir 
um conceito em uma imagem" (MOSCOVICI, 2015[2003], p. 71-72). Logo, a objetivação é o mecanismo que associa as palavras e os nomes a conceitos ou a imagens.

De acordo com Moscovici (2015[2003]), a ancoragem e a objetivação são formas que os sujeitos têm de trabalhar com a memória. Ancorar é a forma que temos de superar o distanciamento e a resistência ao desconhecido. Nomear e classificar nos aproxima, tornando o objeto familiar, encaixando-o em uma categoria já existente em nosso universo. Esse mecanismo tem por finalidade facilitar a interpretação da realidade e formar opiniões.

O processo de objetivação, por outro lado, transforma as palavras, derivadas da classificação do processo de ancoragem, em conceitos e imagens. Segundo o autor supracitado, objetivar é "descobrir a qualidade icônica de uma ideia, ou ser impreciso; é reproduzir um conceito em uma imagem. Comparar já é representar, encher o que está naturalmente vazio, com substância" (MOSCOVICI, 2015[2003], p. 72). Nas palavras do autor, objetivar é perceber a imagem de uma ideia, ou seja, conceituar por meio de ícones quando nos faltam palavras para nos referirmos ao objeto.

Como tem se destacado nesta seção, para que um conhecimento possa ser considerado como tal, deve estar presente na vida cotidiana das pessoas e ter sido elaborado coletivamente, a partir do contato com os grupos sociais. Essa construção coletiva e social influencia o modo de interpretar, o modo de agir e o modo de pensar desses grupos. A maneira como os alunos participantes da pesquisa constroem a definição da redação do ENEM afeta a maneira como os membros desse grupo agem com relação ao exame. Se uma representação for, por exemplo, "a redação do ENEM é um castigo", os alunos podem não se interessar por esse objeto de ensino. Assim sendo, estudar as RS não só nos permite descobrir o pensamento simbólico desses alunos, mas também, a partir disso, compreender como atuam diante desse objeto (MOSCOVICI, 2012[1961]).

$\mathrm{Na}$ seção seguinte, em diálogo com a Teoria das Representações Sociais, abordamos conceitos-chave da Teoria Dialógica do Discurso, no intuito de explicitar a fundamentação teórica que embasa nossa prática de ensino de escrita em um IFPR.

\section{As discussões do Círculo de Bakhtin}

Ao tomarmos as RS na acepção de Guareschi (2012[1961]), já citada anteriormente, é impossível dissociá-las da linguagem, haja vista que é fundamental na elaboração das RS, já que é nela e por meio dela que expressamos nossas opiniões, experiências, saberes e identidades. Todas as atividades humanas estão permeadas de linguagens, que se materializam em enunciados, sejam eles verbais (orais, escritos), ou não verbais. Esses enunciados são produzidos nas relações dialógicas que ocorrem nos distintos campos da atividade humana, desencadeando outros enunciados em situações concretas de interação (VOLÓCHINOV, 2017[1929]).

A Teoria Dialógica do Discurso concebe a linguagem em um viés histórico, cultural e social. De acordo com Brait (2017), nessa perspectiva teórica, compreende-se a linguagem de forma social e dialógica, isso porque os sujeitos, ao interagirem, expressam pontos de vista, informações, concordam ou discordam entre si. Ao produzirem seus enunciados, baseiam-se em dizeres já produzidos e provocam uma resposta, que pode ser imediata ou não. Assim é a cadeia infinita da comunicação. Dessa 
forma, podemos afirmar que é praticamente impossível desvincular a linguagem das demais atividades humanas, haja vista que necessitamos dela em todas as ações que desenvolvemos, pois é pela linguagem que se estabelecem relações axiológicas, de modo que não é possível defini-la como um instrumento neutro, abstrato e apenas como forma linguística. Compreender a linguagem dessa forma seria negar as condições de sua gênese, que se dá em usos concretos.

Sem a interação não há produção de discursos, ou seja, o sujeito, no momento da produção do seu discurso (oral, escrito, multimodal, multissemiótico), se orienta por meio das concepções que tem de seus interlocutores. Nesse sentido, todas as formas de manifestação da linguagem envolvem interlocutores e se dão por meio dos enunciados, que se organizam em distintos gêneros do discurso, os quais são endereçados ao(s) outro(s), do(s) qual(ais) esperamos respostas, isto é, fazemos uso da língua para estabelecer e concretizar o contato com o(s) outro(s). Portanto, a linguagem efetiva-se durante a interação discursiva por meio de enunciados que são produzidos no decorrer da vida dos falantes, em suas jornadas de trabalho, nos momentos de lazer, em atividades cotidianas, em resposta a outros enunciados, em uma cadeia ininterrupta que é a linguagem.

Dessa forma, o contexto e as situações nas quais ocorre a interação entre os sujeitos determinam os enunciados, e as condições específicas constituem o que se conhece por gêneros do discurso, ou seja, cada campo de atividade humana produz distintos gêneros do discurso, conforme a sua necessidade (BAKHTIN, 2011 [19521953]). De acordo com o filósofo russo, os enunciados

refletem as condições específicas e as finalidades de cada uma dessas esferas, não só por seu conteúdo (temático) e por seu estilo verbal, ou seja, pela seleção operada nos recursos da língua - recursos lexicais, fraseológicos e gramaticais -, mas também, e, sobretudo, por sua construção composicional (BAKHTIN, 2011[1952-1953], p. 261).

Os gêneros do discurso são, portanto, na ótica das discussões do Círculo de Bakhtin, formas de enunciados mais ou menos estáveis, e cada gênero discursivo apresenta um conteúdo temático, um estilo verbal e uma composição, sendo essas suas dimensões constitutivas. O conteúdo temático refere-se ao conteúdo tratado no gênero e está diretamente ligado ao sentido dos enunciados. De acordo com Baumgärtner (2009), orientada pelos estudos do Círculo de Bakhtin, o conteúdo temático se refere "[a]os temas - conteúdos ideologicamente conformados - que se tornam comunicáveis (dizíveis) através do gênero. Nessa perspectiva teórica, somente a enunciação tomada em toda a sua amplitude concreta, como fenômeno histórico, possui um tema" (BAUMGÄRTNER, 2009, p. 81, acréscimo nosso).

Com relação à segunda dimensão constitutiva do gênero discursivo, o estilo diz respeito ao conjunto de formas gramaticais que o sujeito escolhe para compor os enunciados. Segundo Bakhtin (2011[1952-1953]), “a própria escolha de uma determinada forma gramatical pelo falante é um ato estilístico" (BAKHTIN, 2011 [19521953], p. 269). No estilo também estão incluídos a escolha da variante linguística, a ordem das palavras na oração (sintaxe), os operadores argumentativos que são utilizados em detrimento de outros, enfim, toda a configuração linguística adotada pelo enunciador no momento de produção do enunciado, atrelada sempre ao contexto de produção. 
A dimensão composicional do gênero está relacionada à estrutura e à forma de cada gênero. Não é difícil perceber que a estrutura de uma receita de bolo é bastante diferente de um editorial de jornal, tanto que essa é, normalmente, a dimensão mais trabalhada quando se trata de gêneros do discurso em sala de aula.

Uma vez que tomamos a linguagem como constituinte do processo de interação entre os sujeitos, e que é por meio dela que produzimos e trocamos informações sobre a vida cotidiana, em conversas com a família ou vizinhos, que nos atualizamos sobre os acontecimentos locais e internacionais, nas notícias jornalísticas, por exemplo, que comunicamos descobertas científicas, entre muitas outras atividades, temos de pensar que cada sujeito, ao enunciar algo, imprime ao enunciado concreto seus valores sociais; ou seja, a linguagem não é neutra. Mesmo na comunicação de uma notícia do jornal local, há explícita ou implicitamente o julgamento, a valoração do jornalista que a escreveu. E esse posicionamento está intimamente ligado à história de vida do jornalista, à sua formação acadêmica, ou seja, o seu discurso está impregnado de outros discursos.

O fato de nosso discurso ser composto por outros discursos indica o caráter dialógico da linguagem. Para os teóricos do Círculo de Bakhtin, a linguagem é dialógica, pois os enunciados nunca são novos, o que dizemos baseia-se na "memória discursiva da sociedade" (FARACO, 2009, p. 59). Os enunciados também têm caráter responsivo, isto é, o que dizemos está sempre orientado para uma resposta a outro discurso e espera-se também uma nova resposta. E, por fim, o enunciado é uma "articulação de múltiplas vozes sociais" (FARACO, 2009, p. 60). Essas vozes, tanto no diálogo cara a cara, quanto em palestras, aulas ou em enunciados escritos, multissemióticos (romances, contos, charges, poemas) encerram outros enunciados que dialogam entre si. Nas palavras de Costa-Hübes (2017), o dialogismo refere-se ao "encontro de vozes, discursos, enunciados que ancoram um projeto discursivo; são as reenunciações dos jáditos que se (re)organizam e se projetam na construção arquitetônica de um textoenunciado, uma vez que todo discurso está voltado para uma resposta" (COSTAHÜBES, 2017, p. 555).

Nessa perspectiva, podemos pensar na argumentação que o aluno desenvolve na escrita da redação do ENEM. Nesses enunciados estão inseridas as múltiplas vozes que constituem o discurso daquele aluno, sujeito social, porém, único, naquele determinado momento e contexto histórico do dia do exame nacional do EM que projetam seus argumentos respondendo, talvez inconscientemente, a enunciados que ouviu durante a sua trajetória de vida. Além disso, espera-se do aluno, como recurso avaliativo do referido exame, que articule outras vozes sociais em seu texto, por meio de dados, estatísticas e repertório cultural advindos da leitura de diversas áreas do conhecimento.

Ao longo dessa seção, refletimos sobre os conceitos de linguagem, enunciado, gêneros discursivos e dialogismo. Após termos destacado alguns conceitos teóricos caros a esta investigação, explicitamos algumas escolhas metodológicas.

\section{Aspectos metodológicos do estudo}

Em nossas análises, a fim de compreender quais são e como são construídas as $\mathrm{RS}$, adotamos a perspectiva da pesquisa qualitativa-interpretativista, uma vez que "o universo da produção humana que pode ser resumido no mundo das relações, das representações e da intencionalidade e o objeto da pesquisa qualitativa dificilmente pode 
ser traduzido em números e indicadores quantitativos" (MINAYO, 2009, p. 21). É nesse sentido que a pesquisa qualitativa é a abordagem mais adequada para respaldar este estudo, que também se caracteriza como interpretativista, pois, no mesmo sentido da pesquisa qualitativa, no interpretativismo interessam as relações sociais e o contexto no qual o sujeito está inserido. De acordo com Bortoni-Ricardo (2008),

\begin{abstract}
Segundo o paradigma interpretativista, surgido como uma alternativa ao positivismo, não há como observar o mundo independente das práticas sociais e significados vigentes. Ademais, e principalmente, a capacidade de compreensão do observador está enraizada em seus próprios significados, pois ele (ou ela) não é um relator passivo, mas um agente ativo (BORTONIRICARDO, 2008, p. 32).
\end{abstract}

Na perspectiva teórica, o estudo está situado no âmbito da Linguística Aplicada (LA) porque esse campo apresenta um caráter indisciplinar, o qual, segundo Moita Lopes (1996), é aquele que atravessa as fronteiras das disciplinas. Neste estudo, as fronteiras são os limites da linguagem na visão do Círculo de Bakhtin e das RS no campo da Psicologia Social.

Embasamos esta pesquisa na LA por acreditarmos ser necessário problematizar sobre as RS acerca da redação do ENEM, a fim de clarear o entendimento dos envolvidos no processo de escrita neste exame, pois, atualmente, a LA não tem como objetivo resolver os problemas de linguagem com os quais se depara, mas sim "procura problematizá-los ou criar inteligibilidade sobre eles, de modo que alternativas para tais contextos de usos da linguagem possam ser vislumbradas" (MOITA LOPES, 2006, p. 20). Por esse ângulo, acreditamos que as reflexões oriundas a partir das análises das RS dos alunos permitirão entrever possibilidades de abordagens diferenciadas sobre a escrita da redação do Enem.

Como já destacado, este artigo apresenta um recorte de nossa pesquisa de mestrado, ainda em desenvolvimento. A geração de dados para o estudo ocorreu em um Instituto Federal localizado na região Centro-Sul do Paraná, durante um curso sobre redação do Enem, ministrado de outubro a dezembro de 2018, para alunos do curso Técnico em Informática integrado ao EM. O corpus foi gerado a partir de: (i) uma entrevista do tipo grupo focal com 10 alunos do $3^{\circ}$ ano, a qual foi gravada em áudio e posteriormente transcrita; (ii) um questionário com duas questões abertas e duas fechadas sobre a redação do ENEM; e (iii) anotações realizadas em diário de campo.

O IFPR iniciou as atividades no ano de 2008 por meio da Lei 11.892, sancionada pelo presidente da República Luiz Inácio Lula da Silva, que, naquele ano, criou 38 Institutos Federais de Educação, Ciência e Tecnologia. Os primeiros campi instalados foram os de Curitiba, Paranaguá e Foz do Iguaçu. No campus onde realizamos a pesquisa, as instalações do IFPR começaram a funcionar em 2016, para atender aos alunos da região Centro Sul do estado. Nesse ano, foram matriculados 80 alunos no curso Técnico em Informática Integrado ao EM.

Os alunos, sujeitos participantes desta pesquisa, fazem o curso de nível médio no período matutino e utilizam o contraturno para participar dos projetos ofertados pelo campus, bem como dos atendimentos individualizados com os docentes. Tanto na Teoria das Representações Sociais quanto nas discussões do Círculo de Bakhtin, o sujeito é visto como um ser sociológico, responsável e dialético, pois carrega consigo os significados circulantes no meio social onde vive e interpreta o mundo conforme sua 
posição social e experiências vividas (MOSCOVICI, 2012[1961]). Ele, ao representar algo, também representa a si mesmo. Esses aspectos permitem compreender os sujeitos, não apenas como seres biológicos, mas sim sociológicos, dialéticos, responsáveis e responsíveis que interagem no meio social no qual estão inseridos (VOLÓCHINOV, 2017[1929]).

Além disso, quando pensamos em pesquisas na área da Educação em geral, e não seria diferente no campo da Linguagem e da Educação Técnica e Tecnológica, tentamos visualizar as melhorias que essas pesquisas podem trazer às vidas dos educandos e da comunidade acadêmica como um todo.

A partir dessa compreensão de sujeitos, convidamos os alunos a participarem de um curso de redação que seria ofertado em contraturno e, de forma voluntária, 10 alunos inscreveram-se no curso e aceitaram participar da pesquisa. Esse curso de redação é uma das práticas de ensino de escrita adotadas nessa instituição que, anualmente, oferece aos discentes, atividades extracurriculares. Uma dessas atividades é o concurso de oratória, com o qual os alunos desenvolvem a oralidade e a escrita, além do projeto de ensino Jornal Estudantil InForma, no qual discentes de cinco turmas do curso Técnico em Informática Integrado ao Ensino Médio escrevem notícias, crônicas, poemas e artigos de opinião para serem publicados em um jornal digital criado por eles no ano de 2018.

Em 2018, ofertamos um curso especifico voltado para a redação do ENEM. Esse curso foi orientado a partir de uma concepção dialógica de linguagem, já que a linguagem se constitui no processo de interação entre sujeitos sociais e históricos em situações de comunicação específicas (BAKHTIN, 2011). Pensando na redação do ENEM como uma situação específica de comunicação, em que os alunos deverão produzir um texto dissertativo-argumentativo, tematicamente orientado e direcionado a uma banca, dialogamos com os alunos acerca dos possíveis temas de redação, a partir da leitura de trechos de notícias, de reportagens e artigos de opinião, de forma semelhante aos textos motivadores que os alunos encontram nas propostas de redação do ENEM.

Além disso, abordamos as cinco competências avaliadas na prova de redação do ENEM, que são:

\footnotetext{
Demonstrar domínio da modalidade escrita formal da língua portuguesa. Compreender a proposta de redação e aplicar conceitos das várias áreas de conhecimento para desenvolver o tema, dentro dos limites estruturais do texto dissertativo-argumentativo em prosa. Selecionar, relacionar, organizar e interpretar informações, fatos, opiniões e argumentos em defesa de um ponto de vista. Demonstrar conhecimento dos mecanismos linguísticos necessários para a construção da argumentação. Elaborar proposta de intervenção para o problema abordado que respeite os direitos humanos. (BRASIL, 2019, p. 6).
}

Ao expor sobre as competências, explicitamos aos alunos como se dá a atribuição dos pontos em cada uma delas. Posteriormente, nos dedicamos a trabalhar com o gênero redação do ENEM, apresentando aos alunos as três dimensões desse gênero discursivo: o conteúdo temático, o estilo e a construção composicional.

Em primeiro lugar, demonstramos que o conteúdo temático é o recorte do tema dado nos comandos e nos textos base da proposta, abordando, normalmente, problemas sociais. Em segundo lugar, trabalhamos com o estilo verbal que o gênero requer, como o emprego da modalidade formal da língua, a utilização de elementos coesivos que 
promovem a progressão e a coerência do texto, assim como as formas verbais adequadas para construir a argumentação e a autoria. E, por último, tratamos da construção composicional desse gênero, uma vez que é necessário produzir argumentos dentro de certo número de parágrafos, que podem variar de três a cinco, nos quais se inicia com uma introdução, cuja essência é a exposição de informações relevantes sobre o tema e a indicação da tese. Posteriormente, nos próximos dois ou três parágrafos, exibem-se os argumentos que sustentam a tese e conclui-se com um ou dois parágrafos, apontando uma proposta de solução para o problema social apresentado no tema.

Dessa forma, durante o curso, procuramos proporcionar aos alunos momentos de reflexão sobre a situação de comunicação em que se insere o gênero redação do ENEM, uma situação concreta da esfera exame, pois há um enunciador, o aluno que escreve a redação, há um público leitor, um auditório social e a circulação que se dá em sites que dão dicas de como escrever boa redações. Outro aspecto que também pode ser considerado como um diálogo entre os interlocutores é a devolutiva que a banca corretora fornece ao candidato após a correção com o espelho da prova, indicando em quais competências os alunos perderam pontuação. Essa disponibilização do feedback da avaliação do texto em plataforma digital demonstra a responsividade da banca, interagindo, dessa forma, com o candidato.

Todos esses aspectos foram discutidos com os alunos a fim de que eles conseguissem visualizar, no momento da escrita da redação do ENEM, os interlocutores da situação comunicativa e pudessem argumentar de acordo com as exigências do exame.

$\mathrm{Na}$ etapa seguinte à geração dos dados, realizamos as transcrições das gravações e tabulamos as respostas do questionário em quadros com recortes dos comentários dos alunos, aos quais atribuímos nomes fictícios a fim de preservar a identidade de cada um. Essa organização levou em conta os conceitos de ancoragem e de objetivação, que são formas que os sujeitos têm de trabalhar com a memória (MOSCOVICI, 2015[2003]). Sendo assim, os quadros para análise foram organizados da seguinte forma: na primeira coluna, separamos as palavras que nomeavam, classificavam e/ou categorizavam a redação do ENEM (ancoragem); na segunda coluna, indicamos as imagens a que essas palavras podem remeter (objetivação); por fim, na terceira coluna, categorizamos a RS, como mostra o Qua.1 a seguir:

Quadro 1: Processos de ancoragem e objetivação

\begin{tabular}{|c|l|c|}
\hline Ancoragem & Objetivação & Representação Social \\
\hline $\begin{array}{c}\text { Criatividade } \\
\text { Citação } \\
\text { Cheia de regrinhas }\end{array}$ & $\begin{array}{l}\text { Dom } \\
\text { Inspiração } \\
\text { Magia }\end{array}$ & $\begin{array}{c}\text { RS-1 - Existem receitas mágicas para escrever uma boa } \\
\text { redação. }\end{array}$ \\
\hline $\begin{array}{c}\text { Esforço } \\
\text { Angústia } \\
\begin{array}{c}\text { Problema } \\
\text { Diabo }\end{array}\end{array}$ & Castigo & RS-2 - A redação do ENEM é um castigo. \\
\hline
\end{tabular}

Fonte: Elaborado pelas autoras.

$\mathrm{Na}$ primeira linha do quadro, notamos que nos processos de ancoragem e de objetivação na construção da RS-1, para os alunos, existem receitas mágicas para escrever uma boa redação, considerando que utilizaram palavras como: (i) "criatividade", 
que podemos associar a imagens como "dom e magia"; (ii) "citação" (quando o estudante cita frases célebres de autores famosos), que pode estar relacionada à imagem de inspiração; (iii) e a expressão "cheia de regrinhas", que pode também indicar dom e magia. Essa RS ancora-se na ideia que a escrita é um dom, valoração adquirida pelos alunos ao longo da trajetória acadêmica, a qual retrata as vozes dos docentes com os quais aprenderam a escrever, bem como com outros discursos veiculados na mídia.

Já na segunda linha, tem-se a construção da RS-2 da redação do ENEM como um castigo, haja vista que os alunos utilizaram as palavras "esforço, angústia e problema", aliadas ao nome "Diabo", que remetem à imagem de punição. A palavra "Diabo" também faz alusão ao inferno, lugar para o qual, segundo algumas religiões, são enviados os pecadores para serem castigados. As expressões utilizadas pelos participantes da pesquisa refletem, ainda que não absolutamente, as representações que habitam seu imaginário quanto à referida prova. Como dissemos anteriormente, no bojo das RS constam avaliações. Nesse caso, a prova é avaliada como um peso que é colocado aos estudantes, causando-lhes angústia e sofrimento. Isso denota a artificialidade dessa produção escrita, dado que o autor (estudante) não deseja, de fato, dirigir-se a alguém para falar sobre o tema, mas o faz porque é parte do rito para o ingresso em um curso superior de graduação. Discursos valorativos dessa natureza circulam socialmente e são incorporados pelos estudantes, podendo atuar como obstáculo ao seu aprendizado.

Na seção seguinte, analisamos a primeira RS.

\section{RS-1: receitas mágicas para escrever uma boa redação}

Quando os estudantes representam a escrita da redação do ENEM como um processo mágico e criativo, como indicado no quadro anterior, acreditamos que estão associando a escrita a uma concepção de ensino de LP que concebia a linguagem como expressão do pensamento (GERALDI, 1984), tendo em vista que a linguagem era percebida como algo produzido única e exclusivamente na mente do indivíduo. Assim, só escreveria bem aquele que tivesse o dom, que nascesse com essa habilidade.

Essa referência à criatividade pôde ser observada nas falas dos estudantes durante as entrevistas realizadas. O estudante Daniel foi questionado sobre o que sentiu no momento em que escrevia a redação. A sua resposta revela uma representação da escrita como um "passe de mágica" quando cita: "eu queria que a coisa acontecesse ali". Ao dizer isso, o discente indica que não pensa na escrita como um processo e na construção do texto como um momento de interação no qual ele deveria primeiramente informar sobre o tema e, posteriormente, posicionar-se com argumentos a favor ou contra. Ele afirma:

Daniel: Ah, desconforto né, porque... eu queria que a coisa acontecesse ali, e como não era só de assinalar uma alternativa, que nem nas outras questões, então era...ficou mais tenso assim, por conta do tempo e tudo mais.

Nesse excerto, o aluno expressa uma RS da escrita como ato mágico, ou seja, acredita que o ato de escrever é um dom. Garcez (2001), ao abordar sobre técnicas de 
escrita de redação, aponta uma série de mitos e crenças que podem interferir no momento da escrita. Segundo ela, acreditar que somente escreve bem quem possui o dom da escrita é um dos principais mitos que envolvem a produção de textos. A fim de auxiliar os estudantes, após abordar sobre essa crença, a autora explica que a escrita é

\begin{abstract}
uma construção social, coletiva, tanto na história humana como na história de cada indivíduo. $\mathrm{O}$ aprendiz precisa das outras pessoas para começar e para continuar escrevendo. O que vai determinar o nosso grau de familiaridade com a escrita é o modo como aprendemos a escrever, a importância que o texto escrito tem para nós e para o nosso grupo social, a intensidade do convívio estabelecido com o texto escrito e a frequência com que escrevemos (GARCEZ, 2001, p. 2).
\end{abstract}

Para a autora, a escrita é uma construção social, uma vez que envolve sujeitos históricos, que interagem em grupos sociais variados e utilizam a linguagem nas mais diversas atividades que realizam, e dependem de outros sujeitos porque todo o enunciado está orientado para outros enunciados.

A expressão "eu queria que a coisa acontecesse ali" também pode remeter à ideia de que alguns alunos acreditem que escrever é "um ato espontâneo que não exige empenho" (GARCEZ, 2001, p. 1). Tal compreensão de escrita é reforçada muitas vezes pelas próprias práticas que acontecem em sala de aula. De acordo com Geraldi (2011) e Sercundes (2011), é comum observar práticas de escritas que são propostas de improviso, descontextualizadas e sem atividades prévias. Nesses casos, o professor simplesmente ordena que o aluno escreva sobre determinado assunto, estabelecendo um tempo limite para a atividade. O docente espera "que a coisa aconteça ali"; logo, o aluno, em contato com essa prática, pode assimilar a ideia de que escrever é isso, um momento de inspiração.

Não obstante, Garcez (2001) explica que, ao contrário do que muitos pensam, escrever exige esforço, pois quem escreve deve ativar a memória na busca de informações relacionadas ao tema sobre o qual vai escrever e o raciocínio lógico para organizar essas informações. Segundo ela, "É necessário que o redator utilize simultaneamente seus conhecimentos relativos ao assunto que quer tratar, ao gênero adequado, à situação em que o texto é produzido, aos possíveis leitores, à língua e suas possibilidades estilísticas." (GARCEZ, 2001, p. 3).

A escrita não pode ser considerada uma atividade espontaneísta, mas sim um trabalho (GERALDI, 2011), haja vista que muitos elementos estão envolvidos em seu projeto de dizer. O escritor precisa levar em consideração: (i) o contexto de produção no qual o texto está inserido, que neste caso é o ENEM; (ii) o auditório social, que compreende os possíveis leitores, além dos corretores da banca, outros estudantes usuários de sites que fornecem material preparatório para a aprovação no exame; (iii) o gênero discursivo que irá produzir, a redação do ENEM; (iv) o tema proposto para a discussão, momento que o produtor do texto deverá ativar seus conhecimentos sobre o assunto e articular isso às vozes presentes nos textos motivadores do exame; (v) as possibilidades estilísticas da língua que a redação do ENEM permite realizar, isto é, a utilização da norma padrão da língua, a escolha dos operadores argumentativos, dos tempos verbais, dos advérbios e outros aspectos linguísticos e discursivos. 
No mesmo sentido, a estudante Elisa, quando questionada sobre o que sentiu quando finalizou a redação, também ancora sua representação na "metodologia de ensino criativo" (ROJO; CORDEIRO, 2004, p. 8), associando a escrita a um dom, a uma inspiração:

Elisa: Alivio e tristeza porque eu achei que o meu texto ficou muito ruim, mas não tinha mais o que eu fazer, eu não tinha mais criatividade no que escrever e eu tinha que terminar as questões e dai foi aquilo mesmo.

Ao afirmar que não tinha mais criatividade para escrever, a estudante está dizendo que, para escrever um bom texto, precisa de inspiração ou dom. Entretanto, "a linguagem não é um dom divino nem um presente da natureza." (VOLOCHÍNOV, 2013 [1930], p. 141), mas sim um processo que se dá na interação dos sujeitos. Isso não se concretiza na redação do ENEM, posto que a interação a qual a prova de redação se propõe mediar é artificial, dificultando para o aluno se colocar como sujeito que tem, de fato, o que dizer. Em uma interação que não é real, só resta ao aluno tentar recorrer à criatividade, para tentar fazer parecer real.

Nos excertos a seguir, observamos que as estudantes Gabriela e Ana, quando questionadas sobre como costumavam se preparar para a prova de redação do ENEM, referem-se às citações como uma fórmula mágica de obter pontuação alta na redação. Já o estudante Paulo, ao descrever o que sentiu durante a prova, menciona a dica sobre as citações que podem se encaixar em qualquer tema, mas indica que ele não consegue aplicá-la, pois não se lembra das citações.

Gabriela: eu tinha assistido algumas videoaulas, aquelas que a Ana falou, sobre uma guria que ela deu exemplos de citação que cabia em bastantes temas, assim... eu não coloquei nenhuma citação (risos).

Ana: ela colocava algumas coisas que eram tipo mecânicas, tipo, por exemplo, citações que podem se encaixar em qualquer tema de redação, tipo citações, sabe... então tipo tinha ... que precisava seguir uma estrutura eeh me ajudou, também me ajudou, eu lembro que eu coloquei uma citação lá e foi isso, eu acho.

Paulo: E dai a redação, eu fiz depois que eu terminei as questões porque eu não lembro... eu não consigo lembrar citações, então eu utilizei citações que estavam nas perguntas... dai eu lia um conteúdo antes e marcava o que eu... eu poderia usar na redação, né...

Os três estudantes mencionaram o fato de acreditarem que, escrevendo uma citação de algum autor famoso, elevariam a pontuação na avaliação do texto. Essa ideia que ancora a representação de escrita como um dom ou um ato espontâneo está relacionada a diversos discursos que circulam no meio escolar, tanto professores como os sites publicitários que vendem cursos preparatórios para exames, oferecem dicas de citações que enriquecem as redações. Basta uma rápida consulta na internet para localizar aqueles que garantem citações que se encaixam em qualquer tema proposto. 
Nessa direção, Antunes (2006) afirma que as dicas de como escrever bem normalmente não funcionam, haja vista que

as famosas técnicas de redação tão comuns em certos cursinhos de português acrescentam muito pouco e não fazem de ninguém um sujeito competente em escrita. Enfim, escrever um texto é uma atividade que supõe a informação conhecimento do objeto sobre o qual se vai discorrer, além, é claro, de outros conhecimentos de ordem textual-discursiva e linguística (ANTUNES, 2006, p. 168).

Para a autora, a escrita é um processo que vai sendo construído ao longo da jornada estudantil, por meio da leitura e das reflexões sobre o que se lê e do contato com os diversos gêneros discursivos. Ou seja, os alunos poderiam utilizar as citações como forma de dialogar com outros textos, demonstrando repertório cultural compatível ao de um sujeito merecedor de uma vaga no ensino superior, ao invés de simplesmente tentar "decorar" frases soltas de pensadores famosos para "encaixar" em seus textos, como disse a estudante Gabriela, ou de procurar frases nos enunciados das questões das outras áreas para inserir na redação, como afirmou o estudante Paulo. Para ele, a redação somente seria um bom texto se tivesse alguma citação, o que indica também uma representação sobre o que é um bom texto, por isso, faz a ação de "garimpar" frases que possa utilizar em sua redação.

Com base nas palavras dos alunos é possível observar como as RS determinam as ações dos sujeitos. Segundo Moscovici (2012 [1961]), representar algo é repensar, reconstituir elementos de uma dada situação para dar sentido aos futuros comportamentos que envolvem esse contexto, de modo a desempenhar seu papel social de acordo com exigências das relações das quais participa. Ao buscar citações nos enunciados das questões das outras provas, o aluno Paulo, dialogando com os discursos da escola, dos cursinhos, dos professores youtubers, expressa a representação de que uma boa redação é aquela que contém citações.

Após considerarmos a primeira RS, que indicou que os alunos encaram a escrita da redação como um dom, como uma inspiração, além de existirem receitas mágicas para sua produção, a seguir, analisamos a segunda RS.

\section{RS-2: a redação do ENEM é um castigo}

Durante as entrevistas com os alunos, outra representação evocada em seus discursos foi de que a redação do ENEM é um castigo. Representar a escrita da redação dessa forma aponta para várias interpretações sobre as quais estão ancoradas as RS dos alunos. Uma delas nos remete à imagem de uma criança escrevendo "cem vezes" no quadro que não vai mais errar, tal como na Fig. 1. Nesse caso, o ato de escrever atua como uma punição, um castigo. Cumpre somente essa função, pois preencher um quadro de giz com a mesma frase diversas vezes não pode servir para outro objetivo. 
Figura 1 - A escrita como punição

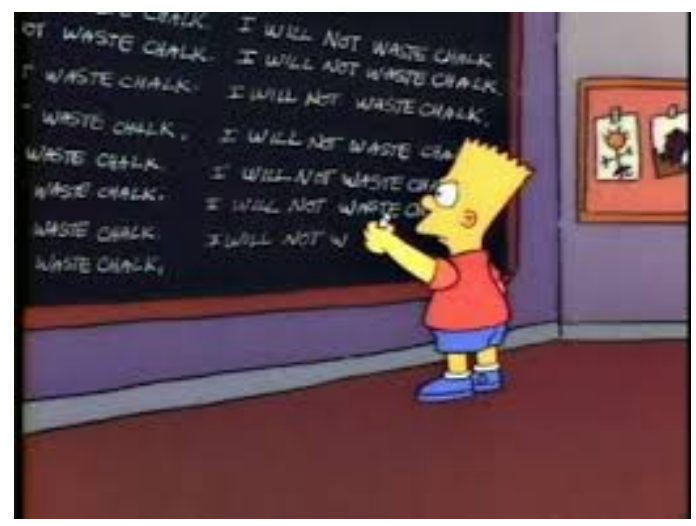

Fonte: https://simpsons.fandom.com/wiki/List_of_chalkboard_gags

Daniel caracterizou a redação como um problema, não como uma ação reflexiva. Para ele, tinha de ser rápido e sabendo a estrutura seria mais fácil resolver o problema. Ele não relatou sobre um possível planejamento do gênero, sobre a tese que defenderia, refletindo, assim, a sua imagem acerca do auditório social para o qual escreveria, tampouco sobre os recursos linguísticos mais adequados para conectar os parágrafos, uma vez que ele também disse que seu texto ficou "desnexo":

Daniel: Ah, eu acho que o pessoal também já tava, algumas pessoas, mais preparados pra isso, assim: "ah, já comecei pela redação, raciocinando...eles já sabiam a estrutura de como produzir o texto e foi bem mais fácil e parece mais rápido assim, pra resolver esse problema. [...] assim, comecei... e começou a ficar desnexo assim, eu acho que a prova ficou com parágrafos assim que não tem nada a ver uma coisa com a outra...

Leonardo, por outro lado, foi direto quando utilizou a palavra "diabo" para nomear a redação. Ancorar a construção dessa representação com essa palavra nos remete diretamente ao ícone inferno, local onde os pecadores são castigados na ótica judaico-cristã. Provavelmente, esse estudante se vê merecedor desse castigo. Em todo momento, ele tentava se mostrar indiferente à prova, tentava dizer que não via dificuldades nela, nem ficava ansioso no momento, porém, em falas posteriores, ele demonstrou que precisava se sair melhor na redação para poder aceder a um curso superior.

Leonardo: ah, eu fiquei um pouco... bah cadê esse diabo dee p... de redação ... aí falei, vou fazendo as questões uma hora aparece, né... 
As estudantes Elisa e Ana expressaram as emoções que sentiram durante a prova de redação. As palavras que escolheram remetem a esforço e angústia, que, de forma semelhante ao que disse Leonardo, remetem a imagens de dor e sofrimento.

\begin{abstract}
Elisa: Minha família já fez ehhh ... sei lá... eles não se preocupam muito com isso... então eles só comentaram que é difícil, mas que eu tenho que me esforçar, esse tipo de coisa.

Ana: Gerou mais angústia ainda porque eu estava bem nervosa, era meu primeiro Enem eee e eu lembro que havia uma dificuldade pra éeh... delega quanto tempo eu ia destinar pra cada parte da prova.
\end{abstract}

Esses depoimentos nos levam a pensar no ato de escrever como algo penoso, que gera sofrimento, o que pode estar ancorado em crenças populares como "quem cedo madruga, Deus ajuda", que contém a ideia de que o sofrimento e o esforço serão recompensados no futuro, ou pode ser um diálogo com o poeta Fernando Pessoa (1993), quando, ao escrever Mar Português, disse "Quem quer passar além do Bojador / Tem que passar além da dor" (PESSOA, 1993, p.76). Talvez o nível médio seja o Bojador para muitos alunos. Transpassá-lo acarretará dores. Muitos jovens sonham sair do ensino médio e aceder à universidade; entretanto, há uma série de barreiras a serem superadas para que isso se concretize.

Algo que pode contribuir para que os alunos consigam alcançar essa meta são as práticas escolares que lhes são oferecidas. Na seção quatro, citamos algumas ações desenvolvidas no IFPR, pela equipe de linguagem, que procuram dar condições ao aluno de ser responsável e responsivo pelos discursos que produz. Assim, ao planejar a escrita de um texto, ele poderá saber o que vai dizer e como vai dizer, de acordo com a situação que the foi indicada, considerando os possíveis leitores do texto e onde circulará.

Nos últimos três anos de docência no IFPR, pudemos observar que a maioria dos alunos reage de acordo com o esperado de seu papel de produtor de textos quando escrevem crônicas, poemas e artigos de opinião para serem publicados no jornal estudantil, os discursos para apresentações nos concursos de oratória da cidade ou a produção de documentário para competir na Olimpíada de Língua Portuguesa. Nessas atividades, normalmente, ao produzirem seus textos, os alunos não reclamam ao revisarem ou reescreverem seus textos, adequando-os em função do veículo onde será publicado, do público leitor ou da norma padrão da língua.

Entretanto, ao narrarem como foi a escrita da redação do ENEM, descrevem-se como incapazes de revisar e de reescrever. Talvez pensem dessa forma porque percebem essa atividade de escrita como artificial, e que considerem a interação proposta na redação fictícia, dado ao caráter do gênero redação-exame.

Inconscientemente, os alunos podem sentir dificuldades em revisar e corrigir suas redações por entenderem que essa é a função do professor-corretor, como fica evidenciado nas respostas de Ana e Gabriela,

Ana: Uma coisa que tive muito é um sentimento muito nítido que eu senti, quando eu terminei, é tipo ... eu não consigo mais ler isso aqui, só que eu sei que isso aqui não tá coeso, eu sei que isso daqui não tá na maneira que devia ser, mas vai ter que ser isso aqui que vai ser entregue... não sei se tem erro de Português, não sei o que tem mais, mas a minha mente não 
consegue mais revisar isso aqui, se eu ler de novo eu não vou extrair nada de diferente que já tem aqui, não vou poder mudar, e vai sé isso mesmo, aí passei a limpo e entreguei... (risos)

Gabriela: é, então... chegou uma hora que eu não estava mais entendendo o que eu estava escrevendo e eu precisava entregar aquilo, como a Ana falou, não fazia... eu sabia que tinha palavras erradas... uma palavra eu tenho certeza que estava errada, mas não tinha noção do que que estava errado... ehhh, eu só mesmo passei a limpo e entreguei o que eu tinha feito com base ali.

Considerar-se incapaz de fazer ajustes de ortografia pode estar vinculado ao fato de enxergarem-se como alunos passivos, que dependem da caneta vermelha da professora apontando seus desvios com relação à norma padrão da escrita. Elas não se veem como produtoras de texto com um propósito do que dizer, a quem dizer e como dizer.

Ressaltamos que a situação de produção de texto durante a redação do ENEM pode ser vista como fictícia. Ainda que a proposta de redação do ENEM ofereça condições sobre o que dizer, como o tema e trechos de notícias ou reportagens e, normalmente, um infográfico sobre o tema, e como dizer "escreva texto dissertativoargumentativo", os alunos não se sentem à vontade para escrever esse gênero discursivo, talvez por encararem essa atividade como a escrita da "velha dissertação escolar" na qual se produz redação somente para o professor corrigir e apontar as falhas.

Ao comparar a escrita de textos dentro e fora da escola, Antunes (2003) indica que nesta ocorre uma escrita "sem função, artificial, mecânica, inexpressiva, descontextualizada, convertida em puro treino e exercício escolar, que não estimula nem fascina ninguém, pois se esgota nos reduzidos limites das próprias paredes escolares." (ANTUNES, 2003, p. 50).

Nesse trecho, a autora está se referindo a atividades de escrita realizadas em sala de aula que não contemplam um contexto real de interação entre interlocutores, servem, na maioria das vezes, para a avaliação da escrita. O aluno sabe que vai escrever para a professora ler e corrigir, logo, não há uma situação de comunicação, nem circulará fora da sala de aula e nem terá outros leitores.

Como destacamos na seção anterior e nesta, acreditamos que a reação dos alunos, ao realizarem a prova do ENEM, é guiada pelas RS que construíram acerca delas, as quais, por sua vez, dialogam com os discursos e as práticas de ensino a que estão acostumados.

\section{Considerações Finais}

Esse estudo interdisciplinar, que articulou a Teoria Dialógica do Discurso e a Teoria das Representações Sociais, procurou apresentar, de modo parcial, as RS acerca da redação do ENEM dos alunos do $3^{\circ}$ ano do Curso de Informática Integrado ao Ensino Médio de um campus do IFPR, descrevendo algumas práticas de ensino de escrita adotadas nessa instituição de ensino. 
Nesse sentido, a partir das reflexões acerca dos processos de construção das RS e do conceito de dialogia, entendemos que os sujeitos necessitam nomear o desconhecido a fim de torná-lo familiar (MOSCOVICI, 2015 [2003]), e fazem isso por meio dos processos de ancoragem e de objetivação, construindo, assim, suas opiniões e imagens sobre determinado objeto social, impregnadas de juízos de valor que são produzidos socialmente, constituindo, portanto, as RS.

Do mesmo modo, compreendemos que os sujeitos se utilizam da linguagem para elaborar suas RS, haja vista que é nela e por meio dela que expressamos nossas opiniões, experiências, saberes e identidades. Ao utilizarmos a linguagem, produzimos os gêneros do discurso, que são tipos de enunciado relativamente estáveis e que comportam três dimensões: o conteúdo temático, o estilo e a construção composicional. Esses enunciados são construídos dialogicamente, uma vez que têm caráter responsivo, ou seja, estão sempre orientados para uma resposta a outro discurso que já foi dito ou que ainda o será, além de comportar uma multiplicidade de vozes.

Com relação ao propósito dessa pesquisa, as análises indicaram que os alunos representam a redação do ENEM de duas maneiras. A primeira representação é a de que existem receitas mágicas para obter pontuação alta na redação do ENEM. Tal visão está ancorada na concepção de escrita com um dom, algo destinado a poucos. Essa concepção de escrita desencadeia no aluno a ação de não se preparar adequadamente para a prova, uma vez que ele não leva em conta que a escrita é uma habilidade a ser desenvolvida. A segunda representação é a de que a redação do ENEM é um castigo, que pode estar ancorada na ideia de que é preciso sofrer para ser merecedor de um prêmio. A entrada na universidade seria a recompensa para todo esse esforço e sofrimento.

Acreditar em receitas mágicas faz com que os alunos se preparem de forma equivocada para a prova de redação, uma vez que deveriam pensar no gênero discursivo, na esfera na qual vai circular, no possível público que o lerá. Dessa forma, poderiam se preparar para encontrar um tema, ainda que esse seja desconhecido até o dia do exame, e escrever declarações sobre ele, concordando ou discordando, relacionando-o com fatos históricos já ocorridos e apresentando uma proposta de intervenção para solucionar o problema implícito na temática com a descrição detalhada sobre quem vai fazer a ação, de que forma, com qual recurso e a quem beneficiará.

Além disso, perceber a redação como um castigo também contribui para um desempenho ruim, pois, em vez de se concentrar em dizer algo com sentido, na intenção de convencer o leitor, o aluno passa o tempo pensando em livrar-se do castigo. Consequentemente, a concepção de produtor de textos que o aluno tem si mesmo é negativa, pois todas essas negações sobre a própria capacidade de escrita dos alunos estão imbricadas com as RS que construíram sobre a redação do ENEM e sobre a escrita durante a vida acadêmica.

Talvez, se houvesse um consenso quanto à classificação da redação do ENEM como um gênero discursivo, a redação-exame, como nomeou Oliveira (2016), e se os documentos oficiais que regulamentam a prova explicitassem dessa forma, os alunos fossem capazes de escrever e reescrever seus textos sem esse pesar, esse sofrimento, uma vez que nomear o desconhecido contribui para a aproximação e a aceitação dele.

Outro aspecto a ser levado em consideração é o tempo destinado a essa atividade no exame. Talvez seja necessário sugerir ao órgão competente que destine mais tempo para a redação, como duas horas, pelo menos, em momento separado das demais provas. 
Entretanto, esses aspectos, dada à relevância do assunto, devem ser considerados em futuras pesquisas sobre as RS acerca da redação do ENEM, a fim de verificar como os professores de LP, os documentos norteadores do exame e a mídia a representam, revelando as concepções em torno desse gênero discursivo.

\section{Referências}

ANTUNES. I. Aula de Português: encontro \& interação. São Paulo: Parábola Editorial, 2003.

ANTUNES, I. Avaliação da produção textual no ensino médio. In: BUNZEN, C.; MENDONÇA, M. (Orgs.). Português no ensino médio e formação do professor. São Paulo: Parábola Editorial, 2006, p. 163-179.

BAKHTIN, M. Estética da criação verbal. Tradução de Paulo Bezerra. 6.ed. São Paulo: Martins Fontes, 2011[1952-1953].

BAUMGÄRTNER. C. T. Aspectos constitutivos da história do ensino de língua portuguesa no oeste do Paraná (1960-1979). Tese (Doutorado em Estudos da Linguagem), Universidade Estadual de Londrina, Londrina - PR, 2009.

BORTONI-RICARDO, S. M. O professor pesquisador: introdução à pesquisa qualitativa. São Paulo: Parábola Editorial, 2008.

BRAIT, B. Alguns pilares da arquitetura bakhtiniana. In: BRAIT, B. (Org.). Bakhtin: conceitos-chave. 5.ed. São Paulo: Contexto, 2017, p. 7-10.

BRASIL. Ministério da Educação. Lei $N^{o}$ 11.892/2008. Institui a Rede Federal de Educação Profissional Científica e Tecnológica, cria os Institutos Federais de Educação, Ciência e Tecnologia, e dá outras providências. Brasília: MEC, 2008.

BRASIL. Ministério da Educação. Instituto Nacional de Estudos e Pesquisas Educacionais Anísio Teixeira (Inep). A redação no Enem 2019: cartilha do participante. Brasília: MEC/INEP, 2019.

CHIAPPINI, L. Aprender e ensinar com textos. 3. ed. São Paulo: Cortez, 2000.

COSTA -HÜBES, T. C. A pesquisa em ciências humanas sob um viés bakhtiniano. Revista Pesquisa Qualitativa, São Paulo (SP), v. 5, n. 9, p. 552-568, dez. 2017.

FARACO, C. A. Linguagem \& Diálogo: as ideias linguísticas do círculo de Bakhtin. São Paulo: Parábola Editorial, 2009.

GARCEZ, L. H. do C. Técnica de redação: o que é preciso saber para bem escrever. São Paulo: Martins Fontes, 2001. 
GERALDI, J. W. Concepções de linguagem e ensino de português. In: GERALDI, J. W. (Org.). O texto na sala de aula: leitura e produção. Cascavel: Assoeste, 1984, p. 41-49.

GERALDI, J. W. Da redação à produção de textos. In: GERALDI, J.W.; CHIAPPINI, L. (Orgs.). Aprender e ensinar com textos de alunos. 7.ed. São Paulo: Cortez Editora, p. 17-26.

GUARESCHI, P. A. Apresentação à edição brasileira. In: MOSCOVICI, S. A psicanálise, sua imagem e seu público. Tradução de Sonia Fuhrmann. Petrópolis: Vozes, 2012[1961], p. 7-8.

JODELET, D. Representações sociais: um domínio em expansão. In: JODELET, D. As representações sociais. Tradução de Lilian Ulup. Rio de Janeiro: Eduerj, 2001[1989], p. $17-44$.

MESERANI. S. O intertexto escolar: sobre leitura, aula e redação. 4. ed. São Paulo: Cortez, 2002.

MINAYO, M. C. de S. (Org.). Pesquisa social: teoria, método e criatividade. 28. ed. Petrópolis, RJ: Vozes, 2009.

MOITA LOPES, L. P. da. Oficina de lingüística aplicada: a natureza social e educacional dos processos de ensino/aprendizagem de línguas. Campinas: Mercado de Letras, 1996.

MOITA LOPES L. P. (Org). Por uma Lingüística Aplicada Indisciplinar. São Paulo: Parábola, 2006.

MOSCOVICI, S. A psicanálise, sua imagem e seu público. Tradução de Sonia Fuhrmann. Petrópolis: Vozes, 2012[1961].

MOSCOVICI, S. Representações sociais: investigações em psicologia social. Tradução de Pedrinho A. Guareschi. 11. ed. Petrópolis: Vozes, 2015[2003].

NOGUEIRA, S. dos S. Representações de alunos do Ensino Médio sobre o processo de ensino-aprendizagem de Língua Portuguesa. Dissertação (Mestrado em Letras e Linguística). Universidade Federal de Goiás, Goiânia, 2016.

OLIVEIRA, F. C. C. de. Um estudo sobre a caracterização do gênero redação do ENEM. Tese (Doutorado em Linguística). Universidade Federal do Ceará, Programa de Pós-Graduação em Linguística, Fortaleza - CE, 2016.

PESSOA, F. Mensagem. Autores Portugueses de Ontem 2. Aveiro: Estante Editora, 1993. 
PAULINELLI, M. de P. T.; FORTUNATO, G. C. A redação do Enem à luz dos gêneros discursivos e textuais. RevLet - Revista Virtual de Letras, v. 08, n. 1, p. 282-299, jan/jul. 2016.

RODRIGUES, P. C. A produção textual no ensino médio: os documentos oficiais de ensino, o livro didático e a prova de redação do Enem. Tese (Doutorado em Letras e Linguística). Universidade Federal de Goiás, Goiânia, 2017.

ROJO, R.; CORDEIRO, G. S. Apresentação: gêneros orais e escritos como objetos de ensino - modo de pensar, modo de fazer. In: SCHNEUWLY, B.; DOLZ, J. Gêneros orais e escritos na escola. Campinas: Mercado de Letras, 2004. p. 7-18.

SANTOS, V. M. A. O Enem e $(m)$ representações sociais de alunos da $3^{a}$ série do Ensino Médio de uma cultura escolar local. Dissertação (Mestrado em Letras). Universidade Estadual do Oeste da Bahia, Vitória da Conquista, Bahia, 2017.

SERCUNDES, M. M. I. Ensinando a escrever. In: GERALDI, J.W.; CHIAPPINI, L. (Orgs.). Aprender e ensinar com textos de alunos. 7. ed. São Paulo: Cortez Editora, p. 79-100.

SOARES, M.B. A redação do vestibular. Cadernos de Pesquisa, n. 24. Fundação Carlos Chagas, 1978.

VOLOCHÍNOV, V. N. O que é a linguagem? (1930). In: VOLOCHÍNOV, V. N. $A$ construção da enunciação e outros ensaios. Tradução João Wanderley Geraldi. São Carlos: Pedro \& João Editores, 2013.

VOLÓCHINOV, V. N. Marxismo e filosofia da linguagem: problemas fundamentais do método sociológico na ciência da linguagem. Tradução de Sheila Grilo e Ekaterina Vólkova Américo. São Paulo: Editora 34, 2017[1929].

Recebido em 29 de maio de 2020

Aceito em 29 de junho de 2020 